\title{
Simulation of the Lower Head Boiling Water Reactor Vessel in a Severe Accident
}

\author{
Alejandro Nuñez-Carrera, ${ }^{1}$ Raúl Camargo-Camargo, ${ }^{1}$ \\ Gilberto Espinosa-Paredes, ${ }^{2}$ and Adrián López-García ${ }^{1}$ \\ ${ }^{1}$ Comisión Nacional de Seguridad Nuclear y Salvaguardias, Dirección General Adjunta de Seguridad Nuclear, Doctor Barragán 779, \\ Col. Narvarte, 03020 México DF, Mexico \\ 2 Área de Ingeniería en Recursos Energéticos, Universidad Autónoma Metropolitana-Iztapalapa, Avenida San Rafael Atlixco 186, \\ Col. Vicentina, 09340 México DF, Mexico
}

Correspondence should be addressed to Raúl Camargo-Camargo, rcamargoc@cnsns.gob.mx

Received 30 December 2011; Revised 14 April 2012; Accepted 25 May 2012

Academic Editor: Lluís Batet Miracle

Copyright () 2012 Alejandro Nuñez-Carrera et al. This is an open access article distributed under the Creative Commons Attribution License, which permits unrestricted use, distribution, and reproduction in any medium, provided the original work is properly cited.

\begin{abstract}
The objective of this paper is the simulation and analysis of the BoilingWater Reactor (BWR) lower head during a severe accident. The COUPLE computer code was used in this work to model the heatup of the reactor core material that slumps in the lower head of the reactor pressure vessel. The prediction of the lower head failure is an important issue in the severe accidents field, due to the accident progression and the radiological consequences that are completely different with or without the failure of the Reactor Pressure Vessel (RPV). The release of molten material to the primary containment and the possibility of steam explosion may produce the failure of the primary containment with high radiological consequences. Then, it is important to have a detailed model in order to predict the behavior of the reactor vessel lower head in a severe accident. In this paper, a hypothetical simulation of a Loss of Coolant Accident (LOCA) with simultaneous loss of off-site power and without injection of cooling water is presented with the proposal to evaluate the temperature distribution and heatup of the lower part of the RPV. The SCDAPSIM/RELAP5 3.2 code was used to build the BWR model and conduct the numerical simulation.
\end{abstract}

\section{Introduction}

The loss of coolant in nuclear reactors during scenarios such as operation at full or low power, shutdown, and refueling can cause excessive heatup of the nuclear fuel; this is a beyond design basis accident where the core meltdown is the main focus. The slump of the molten core into the lower head of the Reactor Pressure Vessel (RPV) may produce the failure of it. The accident in Unit 2 of Three Mile Island (TMI-2) in 1979 was an accident with core melt but without failure of the RPV and with intact containment; therefore, the radiological consequences were negligible. The studies of severe accident are oriented into two branches: In-vessel and Ex-vessel where the failure of the RPV or ruptures in some pipes, such as the main steam lines, recirculation pipes, or feed water among others, is the interface parameter. The In-vessel phenomena include the thermal-hydraulics with natural circulation, reflooding, and refilling of the core at high temperature, oxidation of the cladding, hydrogen production, relocation of the molten core into the lower plenum of the RPV, liquefaction of control rods, recriticality, and failure of the reactor vessel. The Exvessel phenomena involve steam explosion, melt dispersion, fission products transport and deposition on structures and components, direct containment heating (DCH) among others [1]; evolution and management of severe accident dependent of the RPV failure, but the uncertainty in the modeling of the phenomenon in bottom of the RPV is very high.

Dupleac et al. [2] developed a detailed model of the bottom of the calandria for the CANDU 6 plant with COUPLE computer code. The objective of the work was the study of In-vessel corium retention by external vessel cooling as a series of strategies adopted in severe accident management guidelines (SAMGs) for CANDU reactor. In the work of Bishnoi and Gupta [1], the containment importance 
during a severe accident, in particular for Pressurized Water Reactor (PWR), is analyzed.

Spengler et al. [3] assess with ASTEC V1 computer code the molten corium-concrete interaction (MCCI) in the pressurized water reactor (PWR). This phenomenon occurs after the failure of the reactor vessel with large amount of molten corium into the reactor cavity. The heat transfer model between melt and concrete is analyzed taking experiments as a reference.

The accident occurred in Fukushima Daiichi Nuclear Power Station on March 11, after an earthquake and tsunami, caused that all of the operating units (units 1,2, and 3) have fuel damage due to the loss of cooling. Conservative calculations indicate that most of the cores of those units are damaged, and some of the fuel is relocated in the bottom head of the RPVs, although this has not been confirmed. Core cooling was eventually established when reactors pressure lowered enough and a fire engine was used to inject fresh water, followed by seawater [4]. The lack of core cooling to compensate for decay heat resulted in excessive fuel temperatures and oxidation of the zirconium cladding. The oxidation of zirconium in a steam environment will create significant additional heat from the exothermic reaction and large quantities of hydrogen. This hydrogen contributed to the increases in containment pressure and to the subsequent hydrogen explosions on units 1,3 , and 4 . There is no real indication of the failure of the bottom of the RPVs, but some of the nozzles of the reactor vessels probably have some leakage.

Recently Ahn and Kim [5] made a comparison between three computer codes with the capability to simulate the reactor vessel lower head. The codes analyzed by these authors are MELCOR, SCDAP/RELAP5, and MAAP4. The capabilities of these codes in predicting core melt accident progression and lower head response differ substantially at each phase of the lower plenum accident progression, due to the different modeling assumptions involved in various initial and boundary conditions, different debris bed configurations and heat transfer correlations, different model parameters, and numerical schemes. Among the main conclusion of their work is that the lower head models employed in the representative US computer codes are rather simple, parametric, and depend greatly on user-specified inputs with a wide range of possibilities, especially for core material relocation (e.g., MELCOR, SCDAP/RELAP5) and debris bed thermal behavior (e.g., MAAP4, SCDAP/RELAP5) in the presence of water coolant in the lower plenum.

A large Loss of Coolant Accident (LOCA) without injection of cooling water due to the failure of the Emergency of Core Cooling Systems (ECCS) is considered. This is a hypothetical scenario in order to cause the core melt rapidly and observe the heating up of the bottom of the RPV and the slump of the core. The primary containment is simulated with boundary conditions, and external cooling of the reactor vessel is not considered. In this work, we present a model of a BWR RPV and its lower head with COUPLE and RELAP5 computer codes. SCDAPSIM/RELAP5 $[6,7]$ code links COUPLE and RELAP5 to simulate the heat and mass between the model of the RPV and the model of the bottom of the RPV. We found that the SCDAPSIM/RELAP5 fails to converge when an important amount of molten material slumps into the lower head of the RPV due to the abrupt change in the temperature in the lower cavity of the reactor.

\section{Reactor Model}

The model of RPV used to simulate the large LOCA is a typical BWR-5 with Mark II containment and is shown in Figure 1 [8]. The SCDAPSIM/RELAP5 computer code was used to simulate the severe accident [6]. In this model, the feedwater (FW), turbine, suppression pool, Control Rod Drive system (CRD), and Emergency Cooling systems (ECCS) such as Low Pressure Core Spray system (LPCS), High Pressure Core Spray system (HPCS), Low Pressure Injection system (LPCI) are represented by boundary conditions along with the Reactor Core Isolation Cooling system (RCIC). Four fuel rods channels (320, 321, 322, and 323) represent the reactor core; each fuel rod is nodalized with twelve axial nodes to model heat transfer and mass distribution in the core. Boundary conditions that represent the primary containment at constant pressure are fixed to simulate the break in the recirculation loop with the time-dependent volumes TDV-998 and TDV-999 that are connected to the valves V-487 and V-484, respectively. These valves are used to simulate breaks in the recirculation lines and they open instantly.

2.1. Features of COUPLE Computer Code. COUPLE [7] is a two-dimensional, finite element, steady-state, and transient heat conduction computer code. This code is used to calculate the heating of the reactor core material that slumps into the lower head of the reactor vessel and is subsequently represented as debris. The computer code takes into account the decay heat and initial internal energy of slumped debris and then calculates the transport by conduction of this heat in the radial and axial directions to the wall structures and the water surrounding the debris. The most important application of the code is the calculation of the heatup of the vessel wall so that the time at which the vessel may rupture can be determined. COUPLE includes the modeling of the following phenomena and conditions: (a) spatially varying porosity, (b) thermal conductivity of porous material, (c) a debris bed whose height grows sporadically with time, (d) radiation heat transfer in a porous material, and (e) natural circulation of melted debris. The limitations of this model are (a) molten material does not flow into an adjacent porous region (this is an important limitation because the calculations of the degradation of the fuel and structure elements can change significantly); (b) oxidation does not occur in the debris bed; therefore, the contribution to the total heat balances is lower and the time of the failure of the reactor vessel could be delayed; (c) fission products release does not occur in the debris bed; therefore, the contribution to the source term is lower than the real. The external cooling of the reactor vessel by flooding of the primary containment is a scenario that is possible to simulate with COUPLE. 


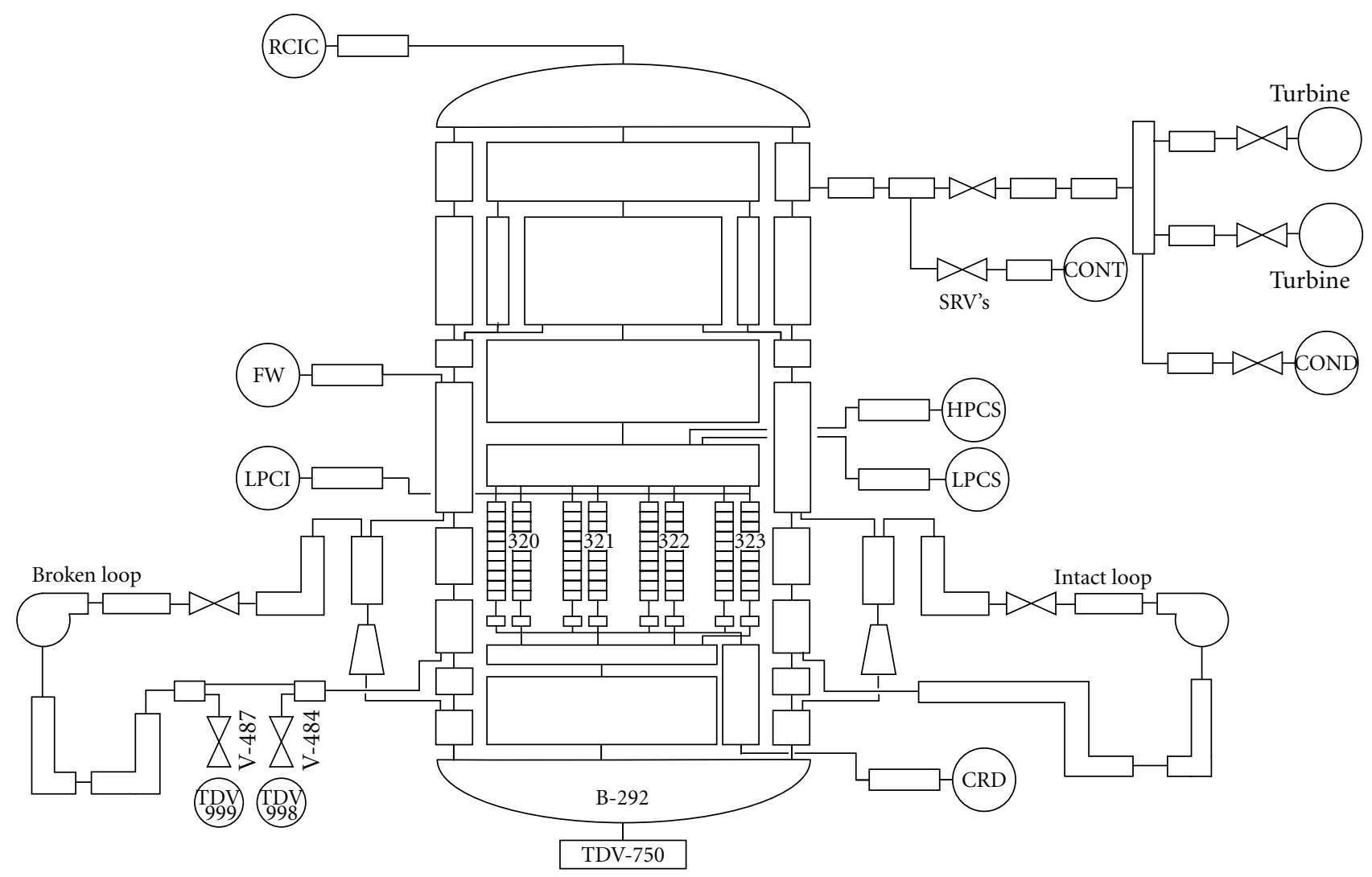

FIgURE 1: SCDAPSIM model of a BWR.

2.2. Model of the Lower Head of the BWR. To simulate the heatup of lower head of the BWR due to the slump of the molten material, a two-dimensional model using COUPLE [6] was developed. The lower head of the vessel is divided in 150 volumes, and each volume is surrounded by 4 nodes of the mesh (Figure 2). The control volumes and the nodes are monitored during the progression of the accident with three parameters, temperature, amount of molten material, and heat transfer. The model developed for BWR consists of 11 nodes in the axial direction by 16 in the radial direction; this nodalization is enough to conduct a detailed study of the lower head of the vessel during a severe accident.

The first 10 volumes represent the outer surface of the reactor vessel insulator, while the volumes 11 to 30 represent the wall thickness carbon steel of the vessel. The volumes 31 to 40 correspond to the $0.0032 \mathrm{~m}$ thick liner of stainless steel. The remaining nodes correspond to the internal volume of the lower head of the RPV. The volume B-292 of the BWR model (Figure 1) is connected to the COUPLE model to calculate the heat and mass transfer from the vessel. An additional time-dependent volume TDV-750 is used to simulate the heat transfer from the lower head of the vessel to the dry well of the primary containment.

The test problems used for the validation of the COUPLE model show that the heat transfer from the molten pool to the lower head is adequate using a relative coarse nodalization in the lower head; a mesh width about onethird of the thickness of the wall of the lower head is accurate enough [9]. This criterion is used in the nodalization of the lower head of the BWR that is presented in this work.

\section{Accident Sequence}

In this work, a simulation of a postulated LOCA at $100 \%$ of full power with simultaneous loss of off-site power and without injection of cooling water from the ECCS is presented (the main events occurred are presented in Table 1). This hypothetical scenario has the objective of a fast degradation of the core in order to observe the slump of molten material in the bottom of the reactor vessel. The external cooling of the reactor vessel by flooding of the primary containment is not considered so as to accelerate the heatup of the bottom of the reactor vessel. Due to the loss of off-site power, the control valves of the turbine close very fast and the recirculation pumps trips in order to avoid the increase of power due to the void fraction collapse.

The lack of cooling in the reactor core causes a high temperature due to decay heat and zircaloy oxidation; therefore, the control rods and the fuel bundles loss their geometry. The molten corium is relocalized in a cooler region of the core forming a thin crust that fails due to gravity forces and high temperature; therefore, the molten pool falls in the bottom of the reactor vessel increasing the temperature of the lower head. In this accident sequence, the fuel rods experience melting and slumping of the cladding, the bed of debris is formed when some drops of corium fall and are 
TABLE 1: Main events of the accident sequence during the simulation of a large LOCA with simultaneous loss off-site power and failure of the ECCS.

\begin{tabular}{|c|c|}
\hline Time (s) & Event \\
\hline 0 & Reactor is operating at steady state condition at $100 \%$ of power \\
\hline \multirow{4}{*}{20} & Guillotine rupture in the recirculation line and loss of AC Power \\
\hline & Scram of the reactor \\
\hline & Trip of all feedwater pumps \\
\hline & No injection of the ECCS is assumed \\
\hline 21 & Vessel water level reaches level 4 (low level) \\
\hline 30 & Feedwater flow decreases to zero \\
\hline 22 & Vessel water level reaches level 3 (low level) \\
\hline 24 & Vessel water level reaches low-low water level (level 2). Main steam isolation valves (MSIV) close \\
\hline 27 & $\begin{array}{l}\text { Vessel water level reaches low-low-low water level (level 1). Second signal to start LPCI and LPCS due to low water } \\
\text { level, but all the ECCSs are considered out of order }\end{array}$ \\
\hline 510 & $\begin{array}{l}\text { The meltdown begins when the region of the core exceeds the temperature for eutectic melting of stainless steel clad } \\
\text { control rods with } \mathrm{B}_{4} \mathrm{C} \text { (boron carbide) absorber material. This temperature is about } 1,500 \mathrm{~K}\end{array}$ \\
\hline 682 & Some drops of corium fall in the lower region of the core and are quenched \\
\hline 1570 & An important amount of molten corium starts to form the molten pool \\
\hline 2300 & $\begin{array}{l}\text { The reactor core reaches the highest temperature }(3000 \mathrm{~K} \text {, fuel bundle } 323 \text {, axial node } 1) \text {. The radius of the molten } \\
\text { pool is } 1.22 \mathrm{~m} \text {. Volume of molten pool is } 3.81 \mathrm{~m}^{3}\end{array}$ \\
\hline 2320 & $\begin{array}{l}\text { The most important amount of melt material slump in the lower head of the vessel when the crust fails, this is observed } \\
\text { in the highness of the bed debris that increases } 0.40 \mathrm{~m} \text { in about } 100 \mathrm{~s} \text {. The radius of the molten pool is } 0.82 \mathrm{~m} \text {, and its } \\
\text { volume is one third lower. }\end{array}$ \\
\hline 2590 & $\begin{array}{l}\text { Volume of molten pool is } 1.16 \mathrm{~m}^{3} \text { with a temperature of } 2873 \mathrm{~K} \text { (fuel bundle } 322 \text {, axial node } 10 \text { ). The total mass of } \\
\mathrm{UO}_{2} \text { in the pool is } 8770 \mathrm{~kg} \text {. The code crashed before RPV failure }\end{array}$ \\
\hline
\end{tabular}

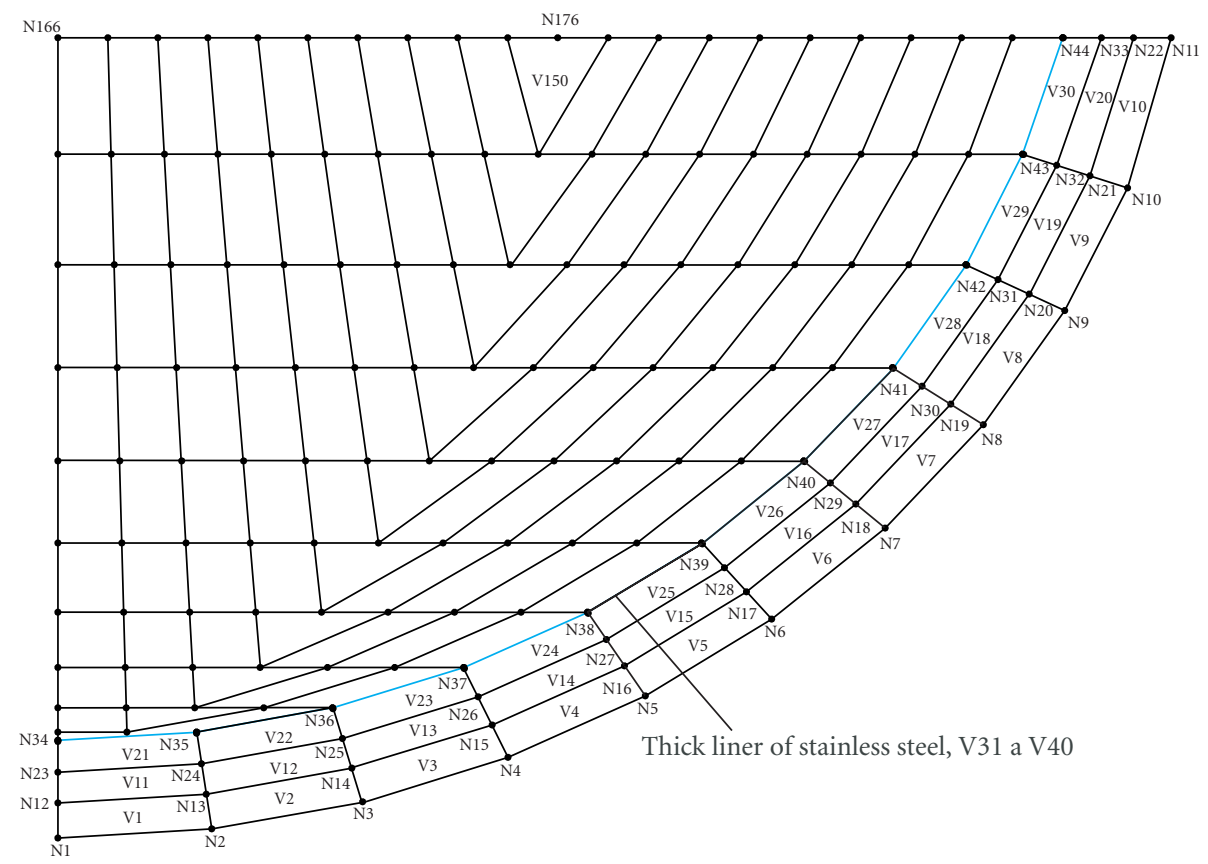

FIGURE 2: Model of the bottom of the reactor vessel for COUPLE computer code. 


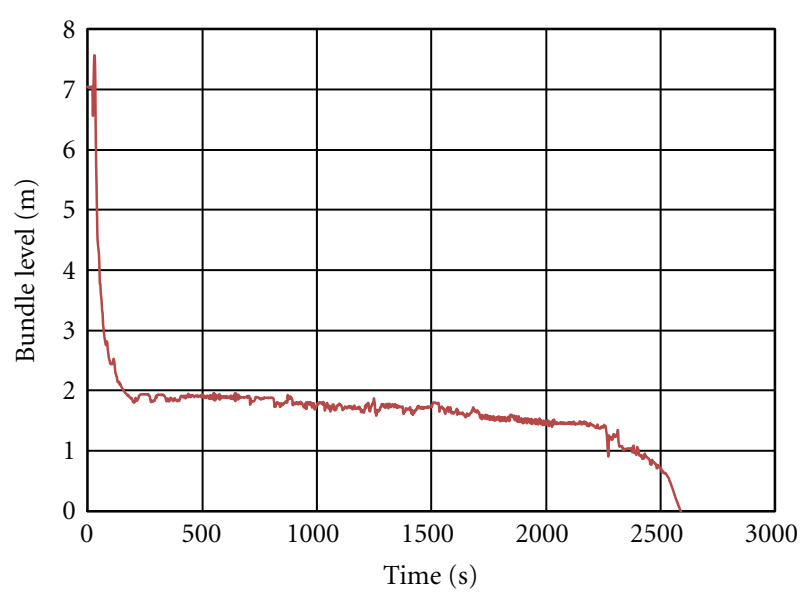

Figure 3: Level of coolant water in the fuel bundles.

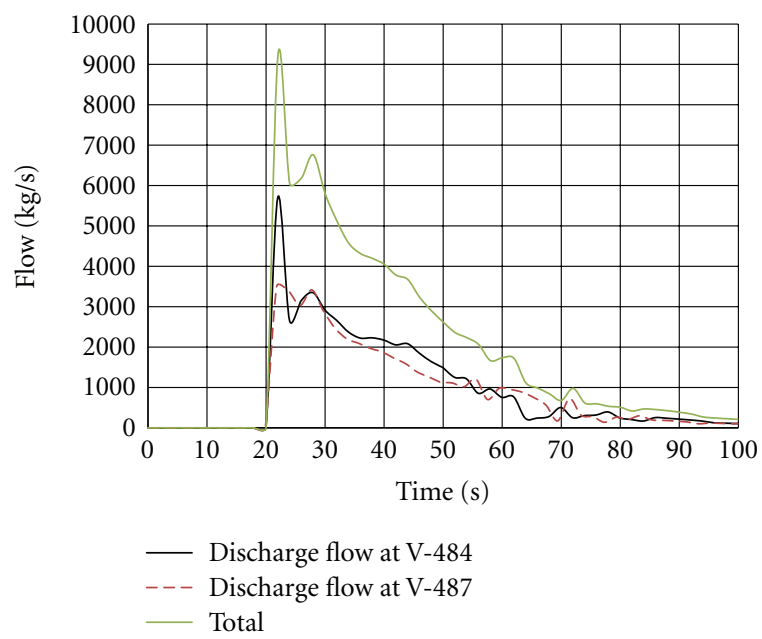

Figure 4: Discharge of coolant flow into the containment from the recirculation broken loop.

quenched by the water that remains in the lower part of the vessel; therefore, the height of the bed debris is increasing during the simulation of the accident.

The failure of the reactor vessel is not observed in this simulation due to the fact that the code crashes because of large amount of corium slumped in the lower plenum. These sudden changes in temperature produce a failure in the computer code to converge.

\section{Results and Discussion}

The numerical results of the simulation of a LOCA at $100 \%$ of full power with simultaneous loss of off-site power and without injection of cooling water from the ECCS are presented in this section. The large LOCA occurs at $20 \mathrm{~s}$ with simultaneous loss of off-site power and without injection of cooling water. Figure 3 shows the fall of water level in the fuel bundles; this quick decrease of cooling water inventory produces the increase of the temperature of the fuel bundles. The bottom of active fuel (BAF) water level is reached at $40.3 \mathrm{~s}$, and it is evaporated after the slump of the molten material into the lower head at 2,590 s. Figure 4 shows the

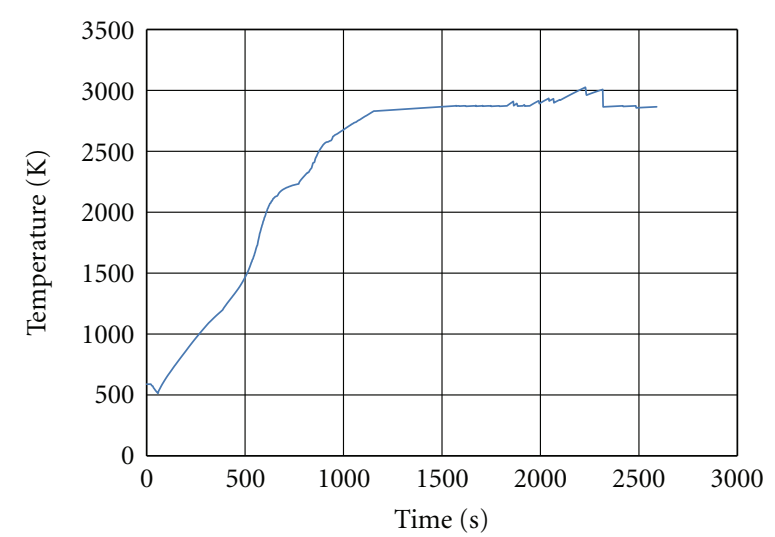

Figure 5: Maximum cladding temperature.

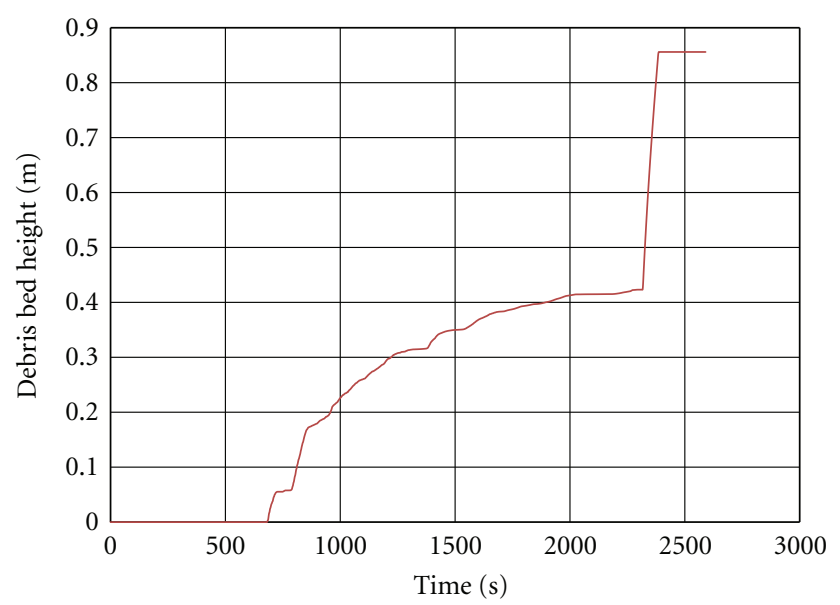

FIgure 6: Debris bed height (in COUPLE mesh).

discharge of liquid to the primary containment after the break of the recirculation pipe through valves V-484 and V487 and the total discharge flow.

The failure of the ECCS and the oxidation of the Zircaloy increase rapidly the temperature of the core. Figure 5 shows the maximum temperature in the core as a function of time. The meltdown begins when the region of the core exceeds the temperature for eutectic melting of stainless steel clad control rods with $\mathrm{B} 4 \mathrm{C}$ absorber material; this temperature is about $1,500 \mathrm{~K}$ and is reached in $510 \mathrm{~s}$.

In this accident sequence, the fuel rods experience cladding melting and slumping; on the other hand, the debris bed is formed due to the failure of the crust of the molten pool, and when some drops of corium fall and are quenched by the water that remains in the lower part of the vessel or are relocated in cooler regions, forming solid particles (debris) that start to deposit in the lower head of the vessel. Figure 6 shows the formation of the debris bed at $688 \mathrm{~s}$.

The molten material does not slump immediately from the core region to the lower head of the vessel. The molten material moves into a colder region and freezes forming a crust that surrounds a pool of molten material known as the "molten pool." The molten pool material freezes because the solidification temperature is much higher than 


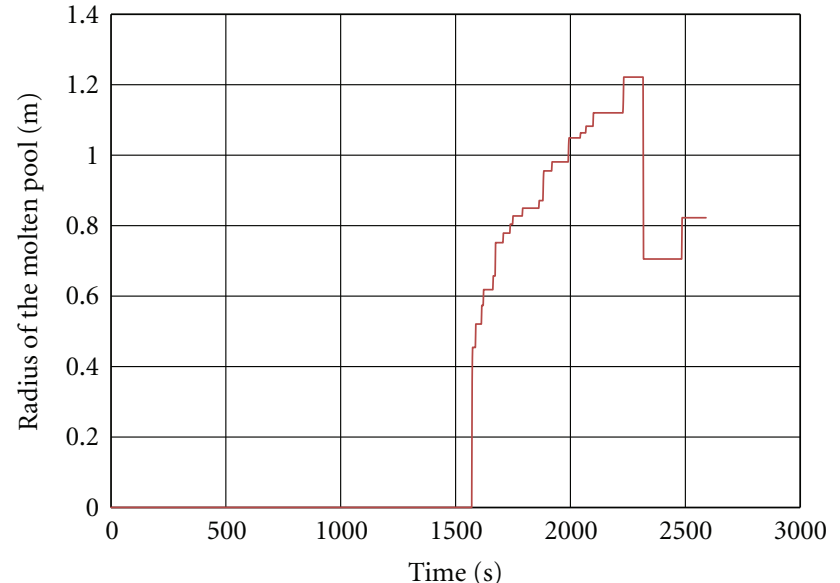

Figure 7: Radius of the molten pool. The failure of the crust is observed at $2320 \mathrm{~s}$.

the liquefaction temperature of the structure, but as the liquefaction continues, the pool may melt the material that provides support and a large amount of molten material may suddenly slump into the reactor vessel lower head.

The feature of the COUPLE assumes a homogeneous temperature distribution over the entire region of the molten pool, taking into account the effect of thermal mixing and turbulent natural convection in the molten pool $[5,10]$. The crust of solidified material is unstable due to contact with the molten pool on one side and liquefied structural material on the other side. After the thickness of the region of liquefied structural material has increased to a certain value, the crust may break up, releasing the molten corium into the lower head of the RPV. The user of the code defines the thickness of the liquefied structural material at which the crust breaks up, in this case a default value of $0.001 \mathrm{~m}$ was chosen.

The molten pool starts to form at $1570 \mathrm{~s}$ (see Figure 7). Table 2 summarizes the in-core molten pool conditions at the final stages of the simulation $(2,590 \mathrm{~s})$. At $1,800 \mathrm{~s}$, the radius of the molten pool deposited in the lower core region is $0.84 \mathrm{~m}$, with a volume of $1.28 \mathrm{~m}^{3}$ and a temperature of $2,870 \mathrm{~K}$. The temperature in the core is increasing and the molten pool still growing due to the slump of molten material. At 2,300 s, the molten pool reaches the higher radius of $1.22 \mathrm{~m}$ (Figure 7) with a volume of $3.81 \mathrm{~m}^{3}$ and a temperature of $3,000 \mathrm{~K}$. At $2300 \mathrm{~s}$, the core reaches the highest temperature, $3000 \mathrm{~K}$ in the fuel bundle 323 (bottom axial node).

The total oxidation heat generation in this time is $4.14 \times$ $10^{5} \mathrm{~W}$ ( $1.8 \%$ of residual heat), and the total mass of the $\mathrm{UO}_{2}$ in the molten pool is $2.7 \times 10^{4} \mathrm{~kg}(66.4 \%$ of the total $\mathrm{UO}_{2}$ in the core). At $2,320 \mathrm{~s}$, the most important amount of molten material slumps into the lower head of the vessel; this is observed in the height of the debris bed that increases $0.40 \mathrm{~m}$ in about $100 \mathrm{~s}$ (Figure 6) due to the failure of the crust at the bottom of the molten pool. The rupture of the crust reduces the radius of molten pool from $1.12 \mathrm{~m}$ to $0.82 \mathrm{~m}$, and its volume drops by one-third. At the end of simulation, the height of the bed of molten material in the lower head reaches

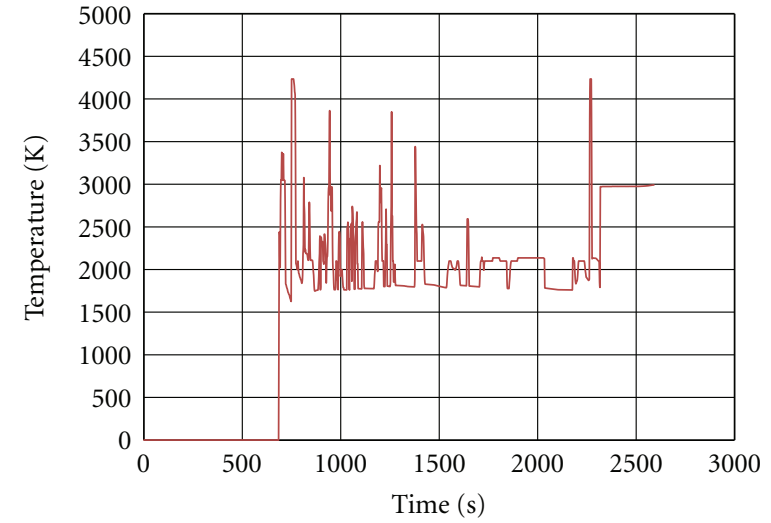

Figure 8: Maximum debris bed temperature in COUPLE mesh.

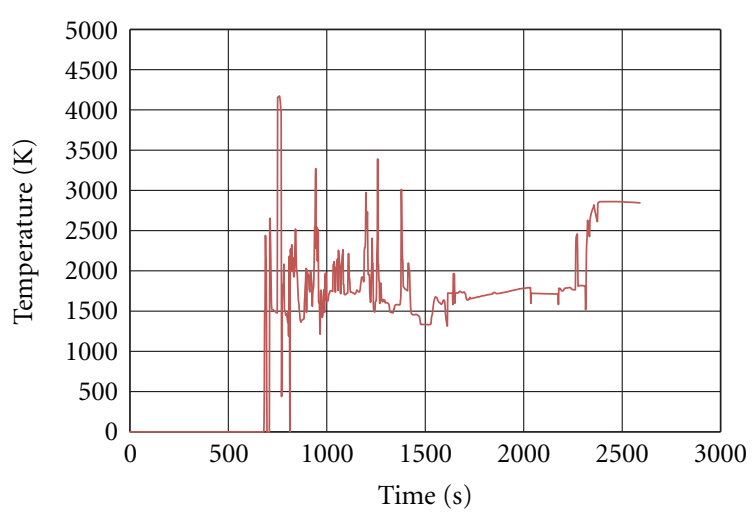

FIGURE 9: Average debris bed temperature (in COUPLE mesh).

$0.85 \mathrm{~m}$ (after 2,590 sec) as can be seen in Figure 6, with an average temperature of $2850 \mathrm{~K}$ (Figure 8).

The maximum temperature of the debris is reached at $750 \mathrm{~s}$ with a temperature of $4,230 \mathrm{~K}$, and another important peak is observed at $2300 \mathrm{~s}$ with a temperature of $4,230 \mathrm{~K}$ as can be observed in Figure 8. The first peak corresponds to the slump of debris into the lower head, and the second one is caused by "molten pool" crust breakup, when the most important amount of molten material and debris slumps into the lower head of the vessel. The average temperature (Figure 9) and maximum temperature of the debris show important oscillations that correspond to the moment of the slump of molten material and debris that are deposited in the lower head during the degradation of the core and then freezes. Successive chunks of molten material and debris fall into the lower head. Some additional large oscillations are caused by numerical instabilities of the code: this is clearly observed in Figure 9, where the average debris bed temperature reaches a temperature of $0 \mathrm{~K}$ at $772 \mathrm{~s}$, this is an important handicap of SCDAPSIM/RELAP5.

A picture of the lower head of the RPV obtained with COUPLE at 2,300 s is shown in Figure 10, just before of the failure of the crust that supports the molten pool. It is observed that the liner of stainless steel and the inner face of the vessel of carbon steel reach a temperature about $1078 \mathrm{~K}$; this temperature is not high enough to provoke a failure of 
TABLE 2: Conditions of in-core molten pool during the accident sequence.

\begin{tabular}{|c|c|c|c|c|c|c|c|c|}
\hline \multirow{2}{*}{ Parameter } & \multicolumn{8}{|c|}{ Time (s) } \\
\hline & 1,800 & 1,900 & 2,000 & 2,100 & 2,200 & 2,300 & 2,500 & 2,590 \\
\hline Effective radius of molten pool (m) & 0.84 & 0.95 & 1.04 & 1.12 & 1.12 & 1.22 & 0.82 & 0.82 \\
\hline Temperature of molten pool (K) & 2,870 & 2,872 & 2,897 & 2,919 & 3,003 & 2,999 & 2852 & 2858 \\
\hline Volume of molten pool $\left(\mathrm{m}^{3}\right)$ & 1.28 & 1.82 & 2.41 & 2.94 & 2.94 & 3.81 & 1.16 & 1.16 \\
\hline Total mass of $\mathrm{UO}_{2}$ in pool $(\mathrm{kg})$ & 9,220 & $1.29 \times 10^{4}$ & $1.70 \times 10^{4}$ & $2.09 \times 10^{4}$ & $2.09 \times 10^{4}$ & $2.67 \times 10^{4}$ & 8,770 & 8,770 \\
\hline Total mass of metallic $\mathrm{Zr}(\mathrm{kg})$ & 0 & 131.0 & 378.0 & 378.0 & 378.0 & 989.0 & 334.0 & 335.0 \\
\hline $\begin{array}{l}\text { Mass of liquefied material in partial } \\
\text { liquefied porous debris }(\mathrm{kg})\end{array}$ & 6,080 & 5,780 & 6,460 & 7,310 & $1.06 \times 10^{4}$ & $1.0 \times 10^{4}$ & 8,750 & $1.19 \times 10^{4}$ \\
\hline Total hydrogen production rate $(\mathrm{kg} / \mathrm{s})$ & 0.083 & 0.0256 & 0.015 & 0.00736 & 0.0191 & 0.00279 & 0.00484 & 0.0650 \\
\hline
\end{tabular}

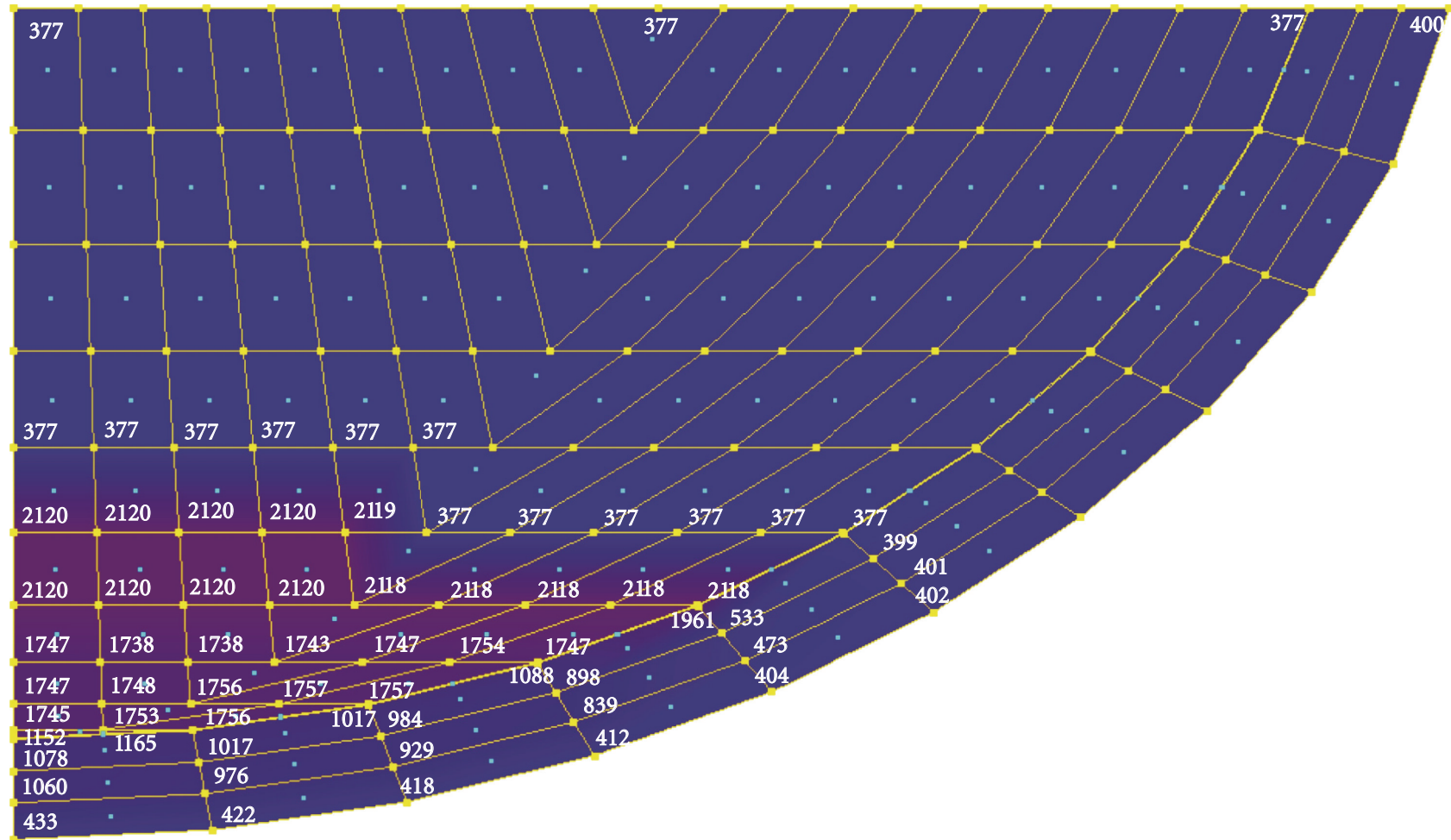

FIgURE 10: Temperature distribution in lower head of the RPV just before the failure of the crust at 2,300 s.

the wall of the reactor vessel. In this time step, the total mass of metallic $\mathrm{UO}_{2}$ in the molten pool is $2.67 \times 10^{4} \mathrm{~kg}$ and the total mass of metallic $\mathrm{Zr}$ is $989 \mathrm{~kg}$ (see Table 2); on the other hand, the combination of $\mathrm{UO}_{2}$ and $\mathrm{Zr}$ form an alloy that may produce a high thermal load in the crust until its failure. In this picture, the temperature of the debris in the lower head has a temperature of $2120 \mathrm{~K}$.

The molten pool falls into the lower head after the rupture of the crust, which increases the debris temperature to $3000 \mathrm{~K}$ and provokes sudden changes in the mass inventory and temperature producing a failure in the computer code to converge due to the fast change in the thermodynamics properties of the steam and water. The temperature of the wall of the reactor vessel is $1756 \mathrm{~K}$, which is beyond the melting point of the stainless steel and carbon steel (1723 K); therefore, the failure of the wall of the lower head is probable but not observed.
The same scenario was simulated using COUPLE with user-defined slumping (simplified option model of SCDAPSIM/RELAP5) for 6,000 s. This simulation did not present problems when the molten material slumps into the lower head of the vessel $(2,300 \mathrm{~s})$ and the simulation ended successfully. Figure 11 shows the debris temperature (maximum and average) using SCDAPSIM/RELAP5 with user-defined slumping option, where the failure of the crust and the increment of the temperature in the debris are observed at $2,320 \mathrm{~s}$; the shape of the curve is smooth without the large numerical oscillations that can be observed in Figures 8 and 9.

The same behavior is observed in Figure 12, where temperature in the wall of the lower head of the vessel (nodes 16 and 17 of COUPLE mesh) is without the large numerical oscillations. The temperature of the wall of the vessel can be obtained by monitoring nodes of the COUPLE 


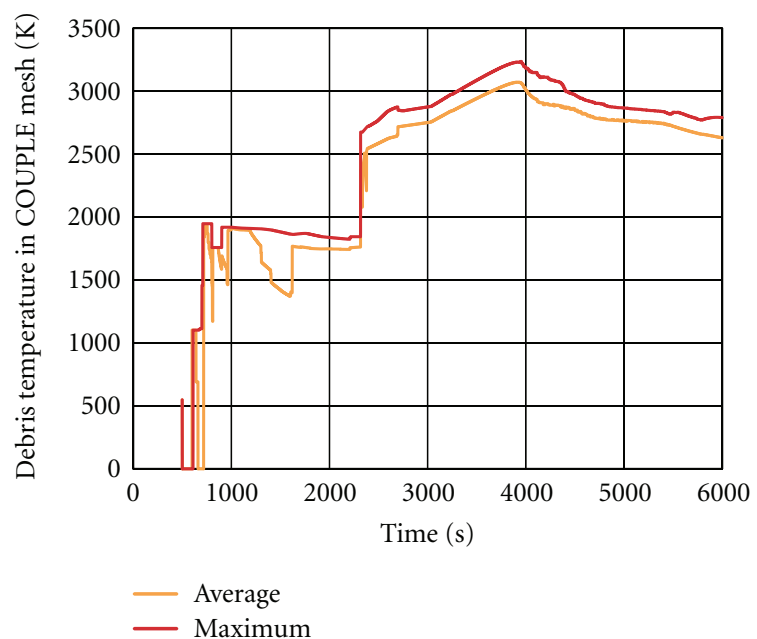

FIGURE 11: Debris temperature obtained with COUPLE with userdefined slumping.

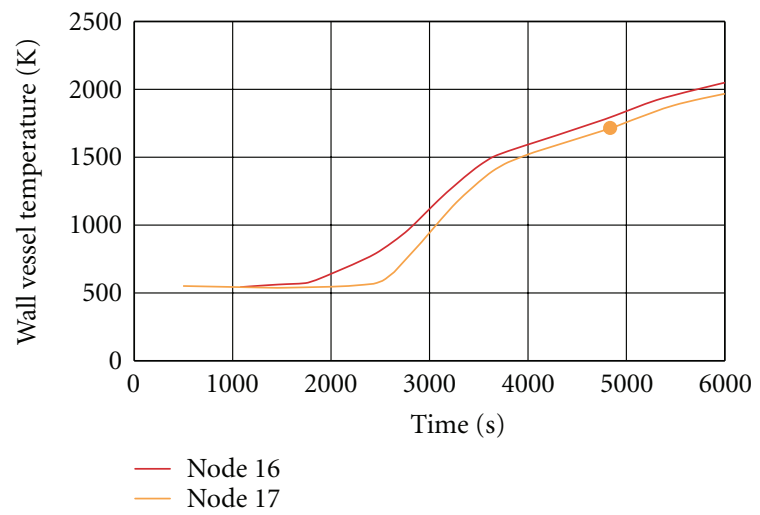

Figure 12: Wall vessel temperature with COUPLE with userdefined slumping. The red dot represents the failure temperature of the lower head of the reactor vessel.

mesh from nodes 12 to 44 . The melting temperature of the carbon steel, $1723 \mathrm{~K}$, is reached from 4460 to $4837 \mathrm{~s}$ in the outer surface of the wall, according with the simulation of COUPLE without coupling RELAP5 and SCDAP, this is represented in Figure 12 by a red dot.

\section{Conclusions}

A model of the reactor vessel lower head with SCDAPSIM/RELAP5 computer code for a BWR is presented. This model was tested with an accident sequence that contemplates a LOCA with failure of the ECCS in order to cause a fast degradation of the core due to lack of cooling water. The SCDAPSIM/RELAP5 has the capability to predict the melting of the core, control rod, and some structures, with an estimation of the main parameter of the molten pool until the failure of the crust. However, SCDAPSIM/RELAP5 computer code presented a problem with the sudden changes in the mass inventory and temperature after the breakup of the crust due to the rapid change in the thermodynamics properties in the steam and water that remains in the vessel lower head. Figures 10 and 11 show that SCDAPSIM/RELAP5 with user-defined slumping option does not report any problems in the simulation of a LOCA for longterm; therefore, the main conclusion is that for long-term simulation where the degradation of the vessel lower head should be observed, the use of COUPLE under this option is highly recommended.

\section{References}

[1] L. R. Bishnoi and S. K. Gupta, "Issues on containment integrity during severe accidents," in Proceedings of the 2nd International Conference on Reliability, Safety \& Hazard (ICRESH '10), pp. 300-305, IEEE, December 2010.

[2] D. Dupleac, M. Mladin, H. Prisecaru, and G. Negut, "SCDAPSIM/RELAP5 investigation on in-vessel corium retention for CANDU 6 plant," in Proceedings of the International Congress on Advances in Nuclear Power Plants (ICAPP '10), pp. 11051111, San Diego, Calif, USA, June 2010.

[3] C. Spengler, H.-J. Allelein, M. Cranga, F. Duval, and J.-P. Van Dorsselaere, "Assessment and Development of Molten Corium Concrete Interaction Models for the Integral Code ASTEC," Forum Eurosafe, Bruxelles (BELGIQUE), 2005.

[4] INPO 11-005, "Special report on the nuclear accident at Fukushima Daiichi Nuclear Power Station," Rev. 0. 2011.

[5] K. I. Ahn and D. H. Kim, "A state-of-the-art review of the reactor lower head models employed in three representative U.S. severe accident codes," Progress in Nuclear Energy, vol. 42, no. 3, pp. 361-382, 2003.

[6] C. M. Allison, G. M. Berna et al., "SCDAP/RELAP5 Users Guide and Input Manual," En, NUREG/CR-6150 EGG-2720. USA, Idaho National Engineering Laboratory, Vol. 3, 1998.

[7] C. M. Allison et al., "SCDAP/RELAP5/MOD 3.2 code manual volume II: damage progression model theory," Tech. Rep. NUREG/CR-6150 INEL-96/0422, Idaho National Engineering and Enviromental Laboratory, New York, NY, USA, 1997.

[8] G. Espinosa-Paredes and A. Nuñez-Carrera, "SBWR model for steady-state and transient analysis," Science and Technology of Nuclear Installation, vol. 2008, Article ID 428168, 18 pages, 2008.

[9] C. M. Allison et al., "SCAP/RELAP5/MOD3.1 code manual, volume 5a: appendix A-SCDAP/RELAP5/Mod 3.2 assessment," Tech. Rep. NUREG/CR-6150, EGG-2720, INEL, New York, NY, USA, 1993.

[10] "RELAP5/MOD3 code manual, models and correlations," Tech. Rep. NUREG/CR-5535, vol. 4, USNRC, 1995. 

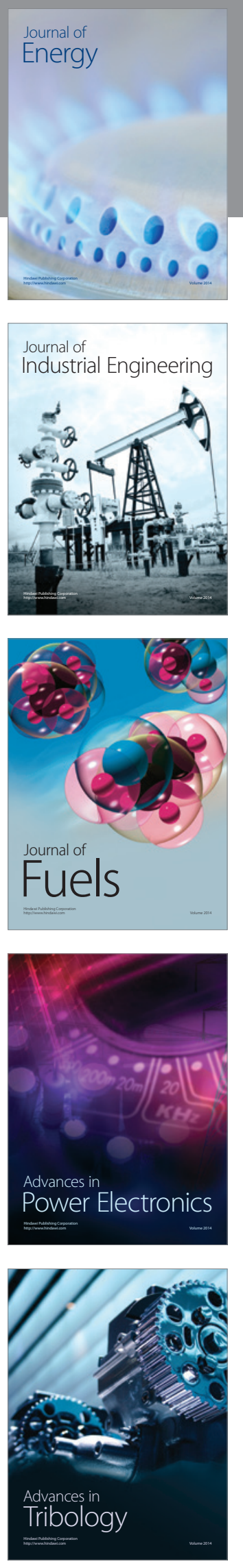
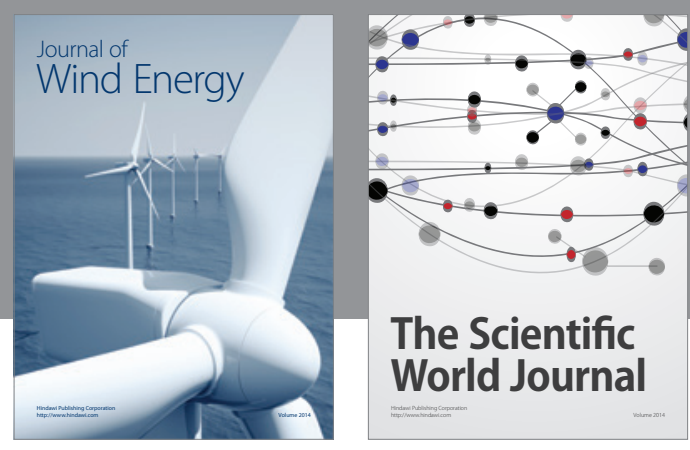

The Scientific World Journal

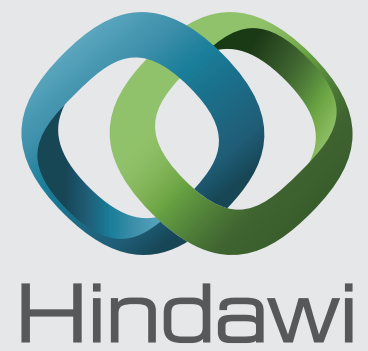

Submit your manuscripts at http://www.hindawi.com
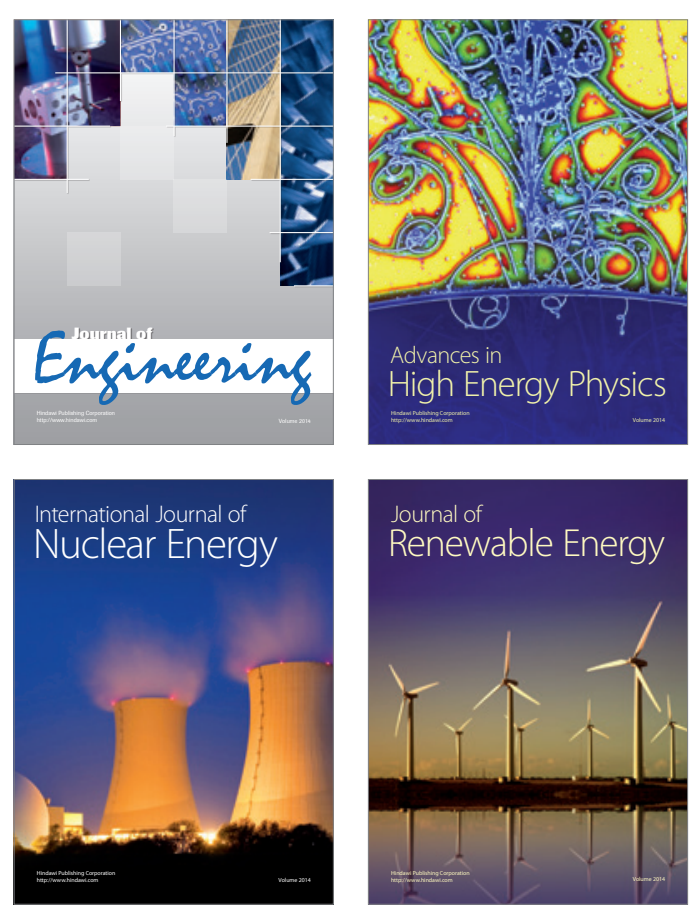

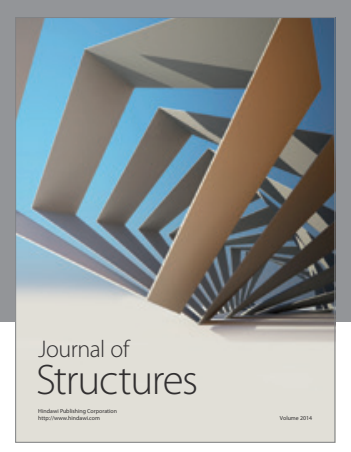

Rotating
Mechinery
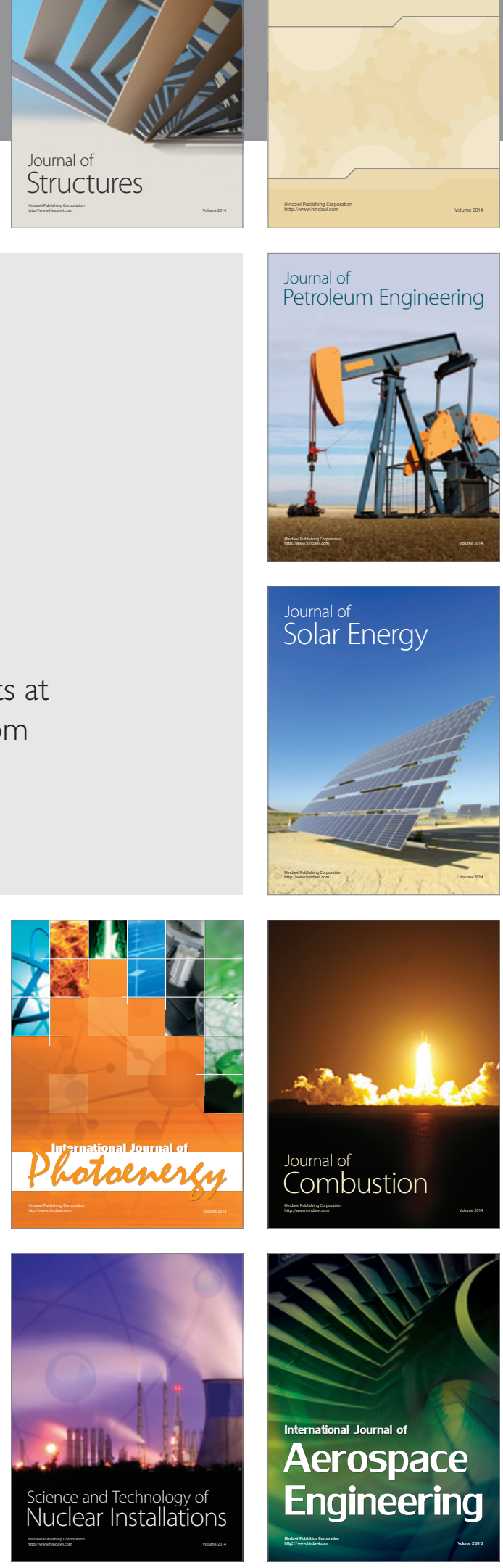